\title{
Lipid mediators in diabetic nephropathy
}

\author{
Swayam Prakash Srivastava ${ }^{1}$, Sen Shi ${ }^{1}$, Daisuke Koya ${ }^{1,2}$ and Keizo Kanasaki ${ }^{1,2^{*}}$
}

\begin{abstract}
The implications of lipid lowering drugs in the treatment of diabetic nephropathy have been considered. At the same time, the clinical efficacy of lipid lowering drugs has resulted in improvement in the cardiovascular functions of chronic kidney disease (CKD) patients with or without diabetes, but no remarkable improvement has been observed in the kidney outcome. Earlier lipid mediators have been shown to cause accumulative effects in diabetic nephropathy (DN). Here, we attempt to analyze the involvement of lipid mediators in DN. The hyperglycemia-induced overproduction of diacyglycerol (DAG) is one of the causes for the activation of protein kinase C (PKCs), which is responsible for the activation of pathways, including the production of VEGF, TGF $\beta 1$, PAl-1, NADPH oxidases, and NFkB signaling, accelerating the development of DN. Additionally, current studies on the role of ceramide are one of the major fields of study in DN. Researchers have reported excessive ceramide formation in the pathobiological conditions of DN. There is less report on the effect of lipid lowering drugs on the reduction of PKC activation and ceramide synthesis. Regulating PKC activation and ceramide biosynthesis could be a protective measure in the therapeutic potential of DN. Lipid lowering drugs also upregulate anti-fibrotic microRNAs, which could hint at the effects of lipid lowering drugs in DN.
\end{abstract}

Keywords: Diabetic nephropathy (DN), Protein kinase Cs (PKCs), Diacylglycerol (DAG), Glyceroshingolpids, Antidyslipidaemic drugs and microRNAs (miRs)

\section{Review}

Introduction

Abnormalities in the lipoprotein metabolism are associated with patients with diabetic nephropathy (DN) [1]. The lipoprotein abnormalities include a higher level of very low-density lipoproteins (VLDL-c), low-density lipoprotein-cholesterol (LDL-c) and a suppressed level of HDL-cholesterol (HDL-c). Researchers have reported that lipoprotein abnormalities are associated with the development of glomeruloscerosis, a process that may share similarities with atherosclerosis [2]. At the same time, clinical studies have shown that in patients with DN, lipid-lowering drugs could be associated with a reduction in the proteinuria but not with a remarkable improvement in the kidney outcome [3,4]. A high level of LDL-cholesterol has been found to predict the development of microalbuminuria in type 1 diabetes [5]. Clinical studies on the association between hyperlipidemia and renal dysfunction in patients with $\mathrm{DN}$ are difficult to

\footnotetext{
* Correspondence: kkanasak@kanazawa-med.ac.jp

'Department of Diabetology \& Endocrinology, Kanazawa Medical University, Uchinada, Ishikawa 920-0293, Japan

${ }^{2}$ Division of Anticipatory Molecular Food Science and Technology, Kanazawa Medical University, Uchinada, Ishikawa 920-0293, Japan
}

perform due to the complex interrelationship between serum lipids, blood glucose, and proteinuria. Watts et al. found that the development of microalbuminuria in a 10-year follow-up was closely related to the baseline serum cholesterol and LDL cholesterol levels [6] in a study on 53 normoalbuminuric type 1 diabetic patients. Parving et al. also found a close association between the serum cholesterol level and progression of renal dysfunction in a 10-year prospective study in type 1 diabetic patients with nephropathy [7]. The baseline level of serum cholesterol was also found to be the independent risk factor for the development of DN in studies of patients with type 2 diabetes [8]. In epidemiologic studies of individuals with glomerular disease or DN, hyperlipidemia predicted a faster loss of kidney function [9]. Krolewski et al. [10] evaluated predictors of fast progression (creatinine after 3 years of follow-up/baseline creatinine 41.5) in 424 individuals with type 1 diabetes and proteinuria. The proportion of individuals with fast progression was $29 \%$ in those with a baseline total cholesterol of $180 \mathrm{mg} / \mathrm{dl}, 24 \%$ for 180 to $219 \mathrm{mg} / \mathrm{dl}, 38 \%$ for 260 to $299 \mathrm{mg} / \mathrm{dl}$, and $48 \%$ for $>300$ $\mathrm{mg} / \mathrm{dl}[10,11]$. The findings persisted after controlling for blood pressure; however, the studies did not control for 
the degree of proteinuria. In the RENAAL study, the baseline total cholesterol (HR (hazard ratio) 1.96 per $100 \mathrm{mg} / \mathrm{dl} \mathrm{ml} \mathrm{higher)}$ and LDL cholesterol (HR 1.47 per $50 \mathrm{mg} / \mathrm{dl}$ higher) were associated with a higher risk of progression to end-stage renal disease [12]. It is unclear from the report whether they controlled for baseline proteinuria. The issue of whether the prior studies controlled for proteinuria is relevant given the strong correlation between the serum cholesterol levels and renal albumin clearance [13].

The beneficial effects of statins on DN progression also remain unclear due to the lack of prospective, randomized intervention studies. Early studies have demonstrated that treatment with the HMG CoA reductase inhibitor pravastatin decreases albuminuria in patients with type 2 diabetes $[14,15]$. However, later studies showed the beneficial effects on albuminuria with HMG CoA reductase inhibitors (simvastatin) in both type 1 or type 2 patients $[16,17]$. These studies involved only a small number of patients, and the follow-up duration was short, making it inadequate for assessing the clinical effects of lipid control in DN.

\section{Lipid mediators as modulators of renal physiology}

The families of prostaglandins, leukotrienes, and related compounds are called eicosanoids and are derived from 20-carbon polyunsaturated fatty acids (dihomo- $\gamma$-linolenic acid, arachidonic acid, or eicosapentaenoic acid [EPA]). These compounds have extremely widespread and diverse biological effects, some of which may be of great importance in the pathophysiology of renal disease. The prostaglandins PGE2 and PGI2 help maintain renal blood flow and glomerular filtration in clinical conditions that are associated with renal functions, and they are generally considered beneficial. PGI3 has been reported to have a similar efficacy to PGI2. Conversely, thromboxane A2 (TXA2) decreases renal blood flow and glomerular filtration [18]. Remarkable increases in the renal production of prostaglandins and/or TXB2 have been reported in humans with chronic renal disease and various animal models of renal disease [19]. Pharmacological or dietary intervention to alter these changes in eicosanoids may provide a means of modifying the disease process. The inclusion of fat sources rich in EPA (for example, marine fish oils) would be expected to decrease the production of dienoic prostaglandins and increase that of the trienoic series [20]. Dietary fish oil supplementation is beneficial in some animal models of renal disease that involve an immune component, for example, murine lupus [21]. A remarkable decrease in the production of dienoic eicosanoids and the increased production of PGE3 (although levels were much lower than those of the dienoic compounds) were noted with fish oil supplementation in one of these studies [21]. It is of interest that a diet high in linoleic acid was beneficial in another subtotal nephrectomy study in rats, although such kind of beneficial effect of linoleic acid was observed in the absence of changes in the urinary excretion of dienoic eicosanoids [22]. Further studies are needed to better evaluate the potential for using polyunsaturated fatty acids in naturally occurring diseases in other species.

\section{Role of PKC activation in DN}

Protein kinase $\mathrm{C}$ (PKC) is involved in signal transduction pathways, cell proliferation, differentiation, cell cycle, and apoptosis. However, the role of PKC in kidney disease has not yet been fully defined. The PKC activation induced by hyperglycemia is likely due to the increase in the 1,2-diacylglycerol (DAG) levels, a physiological activator of PKC, although other co-factors such as phosphatidylserine (PS) or phorbolester (PE) are also known stimulants. Inactivation of the PKC isoforms has been found to counteract many hyperglycemia associated vascular dysfunctions in the kidney [23]. The PKC family has 13 isoforms, which have been classified into three subfamilies based on their mode of activation. The group of classical or conventional PKC (cPKC) consists of the $\alpha, \beta \mathrm{I}, \beta \mathrm{II}$, and $\gamma$ isoforms, all of which depend on calcium $\left(\mathrm{Ca}^{++}\right)$, DAG or its analogue phorbol 12-myristate 13-acetate and, in most cases, phosphatidyl serine (PS) for activation. The isoforms that are independent of $\mathrm{Ca}^{++}$but require DAG and PS are classified as the new PKC (nPKC), and include the subtypes $\delta$, $\varepsilon, \eta$, and $\theta$. The third group of isoforms is that of the atypical PKC (aPKC) $\xi, \mathrm{t} / \lambda, v$, and $\mu$. Their activation does not require $\mathrm{Ca}^{++}$or DAG; they only require PS. Figure 1 depicts the different sources of DAG production and effects on PKC activation. The activation of PKC ( $\beta$ and $\delta$ form) leads to the initiation of many pathological processes responsible for the development of $\mathrm{DN}$. The pathological processes include production of VEGF, TGF $\beta 1$, PAI-1, and NADPH oxidases and activation of the NFkB signaling pathway. Once activated, PKC can transmit signals to the nucleus via different signal transduction pathways. For example, the mitogen-activated protein kinase (MAPK) cascade may be activated. Such diverse functions as cell proliferation, differentiation and cell death are outcomes of particular MAPK members: Raf- 1 can be activated by Ras in some cases after crosstalk with PKC; activated extracellular signal regulated kinases can in turn activate transcription factors such as myc, myb, fos, and jun, thereby enabling the expression of genes encoding enzymes required for key metabolic functions, such as cell proliferation and invasion; and the JNK pathway often initiates cell death, which, in some cases, is stimulated by $\mathrm{PKC}$ isoforms, as recently reviewed by Li and Gobe [24].

Koya et al. reviewed the activation of PKC-associated development of diabetic complication [25]. The inhibition 


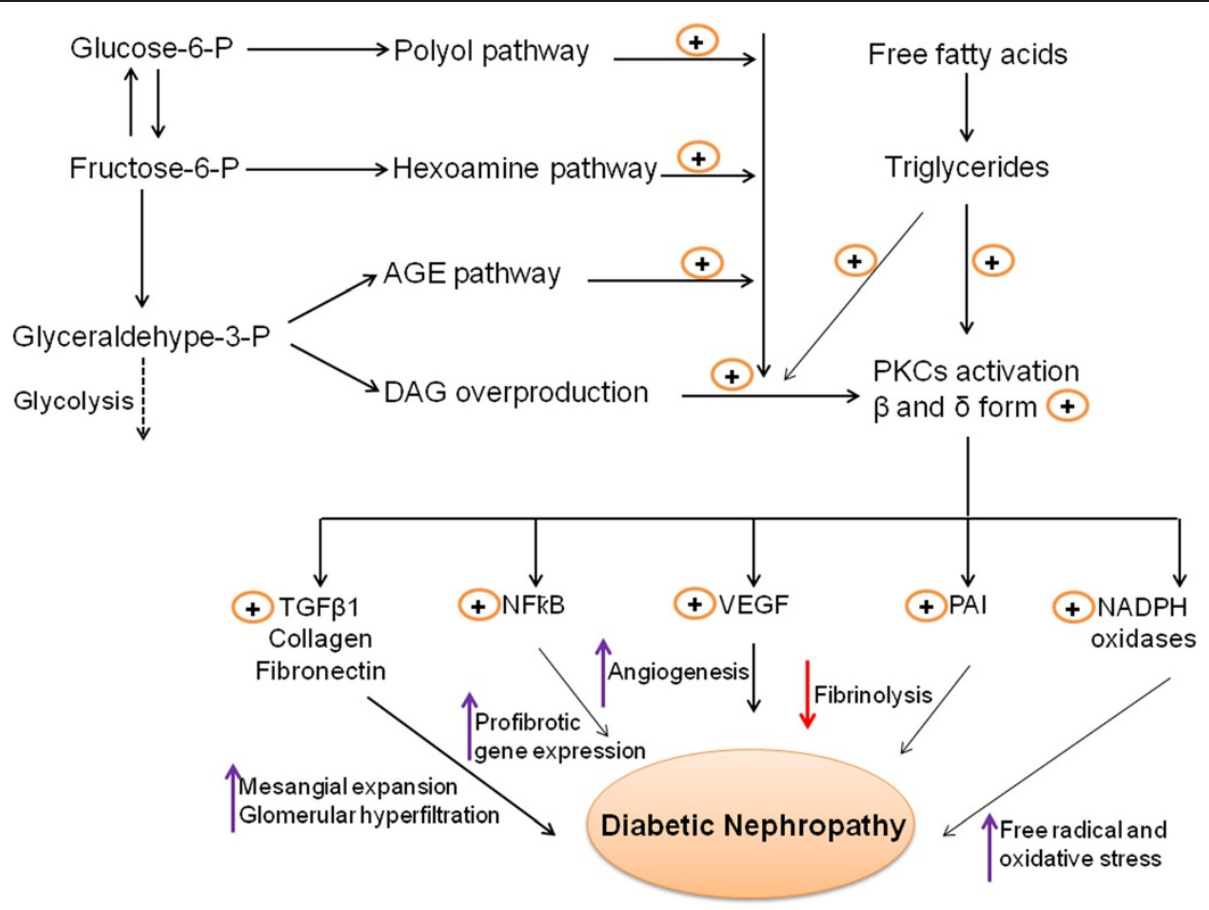

Figure 1 Multiple sources of diacylglycerol (DAG), and DAG-mediated PKC activation could contribute to renal fibrosis. Overproduction of DAG causes the activation of PKC, leading to the initiation and development of diabetic nephropathy (DN). PKC ( $\beta$ and $\delta$ form) primarily upregulates the NFKB gene, TGF $\beta 1$ action, VEGF, PAl, and NADHP oxidases pathway. Increased TGF $\beta 1$, collagen, fibronectin enhanced mesangial expansion, activated NFkB induce profibrotic gene expression, and activated VEGF cause enhanced angiogenesis, and upregulated PAI reduces fibrinolysis, whereas increased NADPH oxidase provides oxidative stress to renal cells; all of these factors could contribute to the development of renal fibrosis.

of PKC $\beta$, a common molecule in diabetes-related renal and vascular injury, holds promise as a novel strategy for improving micro- and macro-vascular complication outcomes in diabetes [26]. Key mechanisms in the pathogenesis of vascular dysfunction in DN are ROS formation followed by the activation of specific isoforms of PKC. The de novo formation of DAG during hyperglycemia activates PKC. Acute hyperglycemia caused the activation of PKC, which could also be associated with rapid endothelial impairment in DN. In the STZ rat model, blockade of the PKC BII isoform with LY333531 prior to hyperglycemia protected nitric oxide formation within the arteriolar wall [27]. Additionally, the increased secretion of inflammatory molecules as a result of hyperglycemia induced PKCs activation, which is involved in oxidative stress and associated with vascular dysfunction in DN. The findings from various studies support an association between the increased secretion of inflammatory molecules, such as cytokines, growth factors, and metalloproteinases, and the development of DN $[28,29]$.

\section{Ceramide in DN}

Ceramides are highly abundant in the kidney, and they regulate various cellular processes, including cell proliferation, apoptosis, inflammation, and cellular signaling.
Ceramide consists of $\mathrm{N}$-acetylated (14 to 26 carbons) sphingosine (16 to 18 carbons). Figure 2 depicts the role of sphingomyelin in the development of kidney disease. The role of sphingomyelin and ceramide in renal physiology was previously reviewed by Hao and Breyer [30,31]. Ceramide is mainly produced from the hydrolysis of sphingomyelin, which is catalyzed by sphingomyelinase [32]. Ceramide can also been generated through the condensation of sphingosine or sphinganine and fatty acyl-CoA by ceramide synthase [32]. The direct targets of ceramide are ceramide-activated protein phosphatase, ceramide-activated protein kinase, and protein kinase $C \xi$. Previous studies have shown that ceramide is involved in the pathogenesis of acute kidney injury caused by ischemic reperfusion, toxic insults, and oxidative stress [33]. In a normal mouse kidney cortex, C24, C22, and C16 ceramides have been identified [34]. Ischemia/reperfusion or nephrotoxic injury (glycerol-mediated myohemoglobinuria, radiocontrast) causes a transient reduction in the renal ceramide levels, which is followed by a two- to three-fold increase in the ceramide levels [35]. The increased ceramide after renal injury is not associated with the enhanced hydrolysis of sphingomyelin because sphingomyelinase expression was not increased (instead, it is decreased) in the experiments [33]. In contrast, hypoxia 


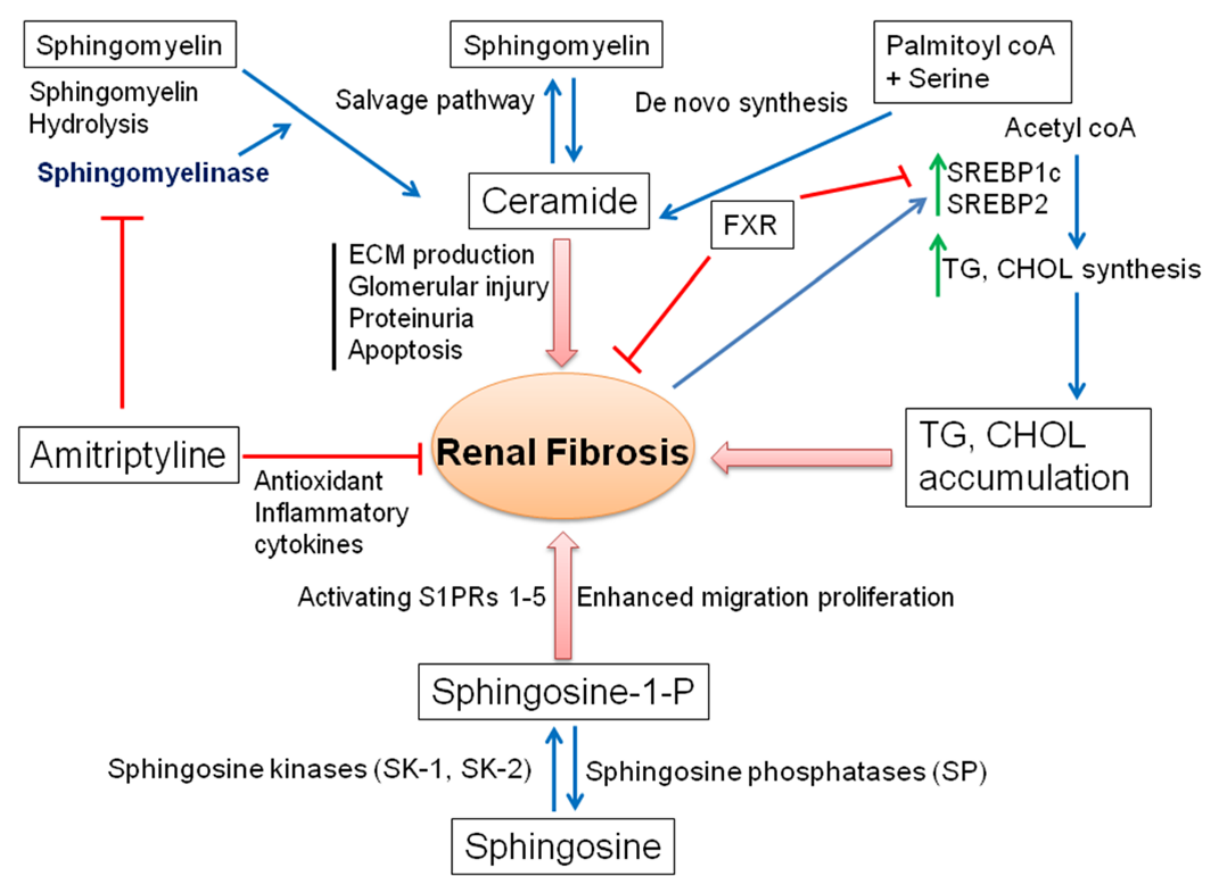

Figure 2 Schematic presentation of ceramide synthesis and its involvement in renal fibrosis. Ceramide is synthesized mainly by three processes: de novo synthesis, the salvage pathway, and sphingomyelin hydrolysis. Ceramide could cause renal fibrosis by enhancing ECM production, glomelular injury, proteinuria, and apoptosis. Triglycerides (TGs) and cholesterol (CHOL) accumulation in the kidney could also contribute to the development of renal fibrosis. At the same time, sphingosine kinase could contribute to renal fibrosis by enhancing cell migration and proliferation. The renoprotective activity of amitriptyline is due to its ability to inhibit the sphingomyelinase enzyme and thereby inhibit ceramide synthesis and to protect against renal fibrosis.

reoxygenation or radiocontrast-induced renal tubular epithelial cell injury is attenuated by the ceramide synthase inhibitor, fumonisin B1, suggesting that increased ceramide synthase activity is responsible for the increased ceramide generation, leading to apoptotic change of the renal epithelial cells [35,36]. Achar et al. found that the tricyclic antidepressant amitriptyline inhibited inflammation, myofibroblast formation, and several other indices of renal fibrosis in ureterally obstructed (UUO) mice [37]. Additionally, there were significant reductions in the expression of $\alpha$-smooth muscle actin ( $\alpha$-SMA), osteopontin, transforming growth factor- $\beta$ (TGF $\beta$ ), monocyte chemotactic protein-1 (MCP-1), and intercellular adhesion molecule1 due to amitriptyline treatment in UUO mice [38]. These pleiotropic antidepressant agents have antifibrotic effects in the kidney and other organ systems. Antidepressants accomplish reduction in kidney fibrosis by several mechanistic possibilities, such as by reducing inflammation, the number of natural killer cells, inflammatory cytokines, chemokines, $\mathrm{H}-1$ receptor, and acid sphingomyelinase activity [39] or increasing anti-oxidant activity in the UUO mice [37]. Amitriptyline can degrade acid sphingomyelinase, an enzyme contributing to ceramide formation, and degradation of acid sphingomyelinase could be helpful in the treatment of DN. Achar et al. [40] studied the renoprotective effect of amitriptyline in UUO mice. The beneficial effect of amitriptyline in the UUO study by Achar et al. [40] could be an inhibition of acid sphingomyelinase that, in turn, inhibits tubular-cell apoptosis and is interstitial in inflammation. A gene knock out experiment to study acid sphingomyelinase would helpful for understanding the protective effect of amitriptyline. Based on the aforementioned reports, we conclude that such a pleiotropic effect of the tricyclic anti-depressant would be a therapeutic challenge in $\mathrm{DN}$.

\section{Antidyslipidemic drugs in DN}

As in the previous Japanese atherosclerosis society (JAS) guidelines of 2007, an LDL goal of $<120 \mathrm{mg} / \mathrm{dl}$ has been set for the high-risk primary prevention patients, and a goal of $<100 \mathrm{mg} / \mathrm{dl}$ is recommended for secondary prevention patients. Therefore, physicians need to help secondary prevention patients in particular achieve the current LDL-c targets using standard lipid management strategies, which can be followed by a more stringent treatment approach. The effect of statins in renal disease have been discussed in detail in many reviews [41,42]. Table 1 summarizes the beneficial effects of lipid lowering drugs on renal outcomes. It is interesting that some of the beneficial effects of statins can be independent of the cholesterol reduction [43]. Different classes of statins can provide renoprotective activity. The potential renal protective 
Table 1 Effect of lipid lowering drugs on the renal outcome

\begin{tabular}{|c|c|c|}
\hline Drugs & Effect on renal outcome & References \\
\hline Statins and Fenofibrate & Reduction in urinary albumin & {$[3,4]$} \\
\hline $\begin{array}{l}\text { Atorvastatins with combine therapy with } \\
\text { glycaemic control }\end{array}$ & Inhibit cardiovascular and renal end points by $50 \%$ in DN patients & [46] \\
\hline \multirow[t]{2}{*}{ Pitavastatin and Pravastatin } & Reduction in urinary albumin in DN patients & \multirow[t]{2}{*}[44]{} \\
\hline & Pitavastatin is more effective than Pravastatin & \\
\hline Rosuvastatin & $\begin{array}{l}\text { Reduction in albuminuria, oxidative stress, and serum cystatin C levels } \\
\text { in DN patients }\end{array}$ & {$[45]$} \\
\hline Atorvastatin & $\begin{array}{l}\text { Not remarkable difference in renal functions between those taking } \\
\text { high or low dose atorvastatin over } 2 \text { years }\end{array}$ & [46] \\
\hline Atorvastatin & $\begin{array}{l}\text { Atorvastatin was effective at decreasing CVD in those with and } \\
\text { without a moderately decreased eGFR }\end{array}$ & {$[47]$} \\
\hline Fenofibrate & $\begin{array}{l}\text { Not remarkable difference in GFR, Provide reno-protection in } \\
\text { moderate renal impairment patients }\end{array}$ & {$[56,58]$} \\
\hline Fenofibrate & Inhibit risk of albuminuria in patient with diabetes & {$[59]$} \\
\hline Fenofibrate & $\begin{array}{l}\text { Acute change in creatinine not associated with adverse effect on } \\
\text { renal outcome }\end{array}$ & {$[56,57]$} \\
\hline Simvastatin (and simvastatin + ezetimibe) & $\begin{array}{l}\text { Does not produce remarkable reductions in measures of renal } \\
\text { disease progression }\end{array}$ & {$[61-63]$} \\
\hline
\end{tabular}

effects of statins include protection against oxidative stress, amelioration of endothelial function through nitric oxide (NO) production and changes in blood rheology. The difference in the renal protective effects of different class of statins are not clearly known in DN lipid-related mechanisms, but this could be due to the statins different pharmacological, pharmacokinetic properties, bioavailability, and distribution in the tissues. A randomized comparison of pitavastatin and pravastatin treatment on the reduction of urinary albumin in patients with type 2 diabetic nephropathy was studied [44]. Pitavastatin was more effective than pravastatin in reducing albuminuria in type 2 diabetic patients with early-stage diabetic nephropathy [44]. Rosuvastatin administration reduced albuminuria, oxidative stress, and the serum cystatin $C$ levels, independent of blood pressure or lipid levels in DN patients [45]. Protection Against Nephropathy in Diabetes with Atorvastatin (PANDA), a randomized, double-blind placebo-controlled trial of high-versus low-dose atorvastatin (1) studies, reported no significant difference in the renal functions between those taking high or low doses of atorvastatin over 2 years [46]. Another report on the effects of atorvastatin on kidney outcomes and cardiovascular disease in patients with diabetes, an analysis from the Collaborative Atorvastatin Diabetes Study (CARDS), revealed a beneficial effect of atorvastatin on the estimated glomerular filtration rate (eGFR), particularly in patients with albuminuria [47]. Atorvastatin was effective at decreasing CVD in those with or without a moderately decreased eGFR and achieved a high absolute benefit [47].

In an elegant study by Zoja et al. [48], the authors reported that a combined angiotensin converting enzyme inhibitor and statin therapy had a remarkable antiproteinuric effect with a significant improvement in the renal function in a severe rat model of passive Heymann nephritis (PHN). The drug combination limited glomerulosclerosis, tubular damage, and interstitial inflammation compared with placebo or drugs alone.

In vitro studies have clearly established that statins influence important intracellular pathways that are involved in the inflammatory and fibrogenic responses [43]. Statins also inhibit the proliferation of cultured mesangial cells and renal epithelial tubular cells through their ability to suppress the formation of intermediate metabolites of the mevalonate pathway, particularly the nonsterol isoprenoids, which seem to be essential in cell replication [49]. Multifactorial strategies that combined glycemic therapy, lipid lowering, blood pressure (BP) control, and aspirin reduced both the cardiovascular and renal end points by $50 \%$ in patients with diabetes and microalbuminuria [50].

Recently, lipid lowering agents in chronic kidney disease were reviewed by researchers, which was of great interest for us [51]. Statins remarkably improve cardiovascular disease (CVD) and the associated mortality in patients with CKD both with and without diabetes who do not require dialysis [52,3]. Statin treatment protects from the injuries caused by the DAG-Activated PKC activation in a variety of ways. These pleotropic effects of statins include improvement in the endothelial function, reduction in the oxidative stress, reduction in the TGF $\beta 1$ level, decline in the level of inflammatory cytokines and sensitization of the Akt/PI3 kinase pathways, inducing the GLUT 4 translocation reviewed by Danesh and Kanwar [53]. The effect of lipid lowering drugs on ceramide formation is not well known. 
Fibrate is another class of lipid lowering drugs to treat hypertriglyceridaemia with residual elevation of non-HDL cholesterol. However, the role of fibrates in patients with CKD has yet to be determined [54]. Investigators in the Fenofibrate Intervention and Event Lowering in Diabetes (FIELD) study [55] randomly allocated [56] 795 participants with type 2 diabetes mellitus to either fenofibrate (200 mg daily) or placebo, with a median follow-up period of 5 years. In this study, fenofibrate treatment reduced the total cardiovascular events (HR 0.89, 95\% CI 0.80-0.99) [55]. This benefit did not differ significantly between groups that had different eGFRs. In another report, the researchers summarized that fenofibrate should be considered as an additional therapeutic option, along with conventional risk-factor management, to further reduce CVD events and mortality and provide reno-protection to patients with diabetes and to those with moderate renal impairment [4]. In a meta-analysis, fibrates reduced the risk of albuminuria progression in patients with diabetes and reduced the risk of major cardiovascular events and cardiovascular death (but not all-cause mortality) in patients with an estimated glomerular filtration rate of 30 to $59.9 \mathrm{~mL} / \mathrm{min} / 1.73 \mathrm{~m}^{2}$ [57]. Fibrates also increase the serum creatinine level after therapy initiation, but this effect could be a response to the blunting of creatinine secretion rather than to true renal injury [58]. In a posttrial analysis of the FIELD and ACCORD datasets, acute changes in the creatinine level with fibrate therapy were not associated with adverse effects on the major clinical renal outcomes.

Researchers introduced a Study of Heart and Renal Protection (SHARP) study, was a double-blind, placebocontrolled trial that aimed to assess the safety and efficacy of reducing LDL cholesterol in more than 9,000 patients with chronic kidney disease (approximately 3,000 of whom were on dialysis at randomization) $[59,60]$. Among the CKD patients, the most common recorded cause of renal disease was glomerulonephritis (19\%), diabetic nephropathy (15\%) and hypertensive or renovascular disease (20\%) [61]. Among the 6,000 patients who were not receiving dialysis at randomization, the average eGFR was 26.5 (SD $13.0 \mathrm{~mL} / \mathrm{min} / 1.73 \mathrm{~m}^{2}$, approximately two-fifths of the patients who were not on dialysis had kidney disease outcome quality initiative stage 3 disease. Among the non-dialysis patients who had a measurement of the urinary albumin to creatinine ratio (ACR), approximately one-fifth had a value in the reference range (ACR $<30 \mathrm{mg} / \mathrm{g}$ ), two-fifths had microalbuminuria (ACR $>30 \mathrm{mg} / \mathrm{g}$ ), and two-fifths had macroalbumiuria (>300 mg/g) [61]. In high-risk populations (such as patients with diabetes), observational studies have shown that there is an approximately log-linear relationship between the risk of death from cardiovascular disease and blood cholesterol, but an analogous association has not been demonstrated in with CKD. In the study, associations between blood cholesterol and cardiovascular mortality were found on a logarithmic scale, among the screenees in the Multiple Risk Factor Intervention Trial (MRFIT) with diabetes $(N=5000)$ and without diabetes $(N=340,000)$ [59]. The study authors also aimed to assess whether lowering LDL cholesterol reduced the rate of loss of renal function in people with CKD, with or without diabetes, who had not commenced dialysis treatment $[59,60]$. Patients were randomly assigned to receive simvastatin $20 \mathrm{mg}$ plus ezetimibe $10 \mathrm{mg}$ daily versus matching placebo. SHARP concluded that approximately a quarter of all heart attacks, strokes, and operations to open blocked arteries could be avoided in people with CKD by using a combination of ezetimibe and simvastatin to lower the blood cholesterol levels [59]. Of the approximately 6,000 patients who were not on dialysis at randomization, allocation to simvastatin plus ezetimibe did not produce significant reduction in any of the prespecified measures of renal disease progression. End stage renal disease is defined as the commencement of maintenance dialysis or transplantation; end stage renal disease or death; and end stage renal disease or doubling of baseline creatinine [61].

\section{MicroRNAs as new regulatory molecules targeted by lipid lowering drugs}

MicroRNAs play an important role in the pathogenesis and regulation of kidney diseases [62,63]. MicroRNAs are non-coding, single strands of 22 nucleotides that exert posttranscriptional control on gene expression by pairing their seed sequences ( 2 to 8 nucleotides at the $5^{\prime}$ end) to complementary sequences that are typically in the 3' untranslated region of target mRNAs. This pairing results in the degradation of the target mRNA and/or the inhibition of its translation. Figure 3 depicts a summary of the microRNA regulation over antidyslipidaemic drugs and renal fibrosis. Statin treatment activates the expression of the miR-143/145 cluster through KLF2 (Kruppel-like family of transcription factor, the zinc finger family of DNAbinding transcription factor) in ECs [64]. MiR-143 and miR-145 are intergenic miRNAs that control the vascular smooth muscle cell (VSMC) phenotypic switch, tumorigenesis, and adipocyte differentiation [65]. ApoE knockout mice showed low levels of vascular miR-143/145 [66]. For instance, the miR-143 to 145 gene locus, which encodes both miR-143 and miR-145, is transcriptionally regulated by a complex composed of serum response factor (SRF) and myocardin or myocardin related transcription factors (MRTFs) $[67,68]$. TGF- $\beta$ and BMP signaling increase miR143 and miR-145 by activating the myocardin and MRTF, respectively [68]. Recently, atorvastatin was found to be associated with the upregulation of SIRT-1 expression via the inhibition of miR-34a [69]. The study elucidated a new mechanism by which statin therapy could improve 


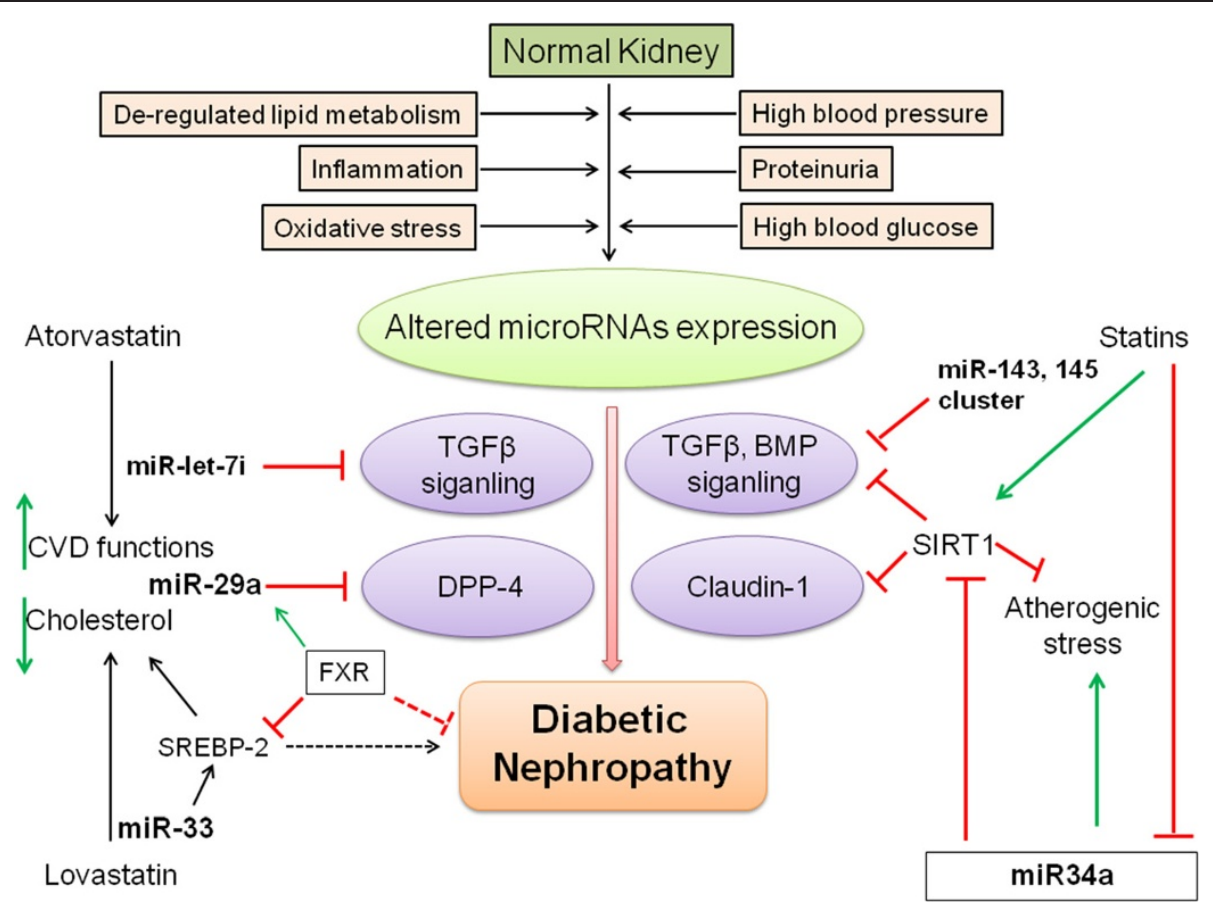

Figure 3 Implications of antidyslipidemic drugs on the antifibrotic-miRs in the protective measures of DN. Altered microRNA expression, as a result of a deregulated lipid metabolism, inflammation, oxidative stress, high blood pressure, proteinuria, and high blood glucose could cause DN by activating transforming growth factor $\beta$ (TGF $\beta$ ) signaling. An elevated DPP-4 level, BMP signaling, and claudin-1 could also be associated with DN. Atorvastatin improves cardiovascular functions by elevating miR-let-7i. miR-let-7i is associated with inhibiting TGF $\beta$ signaling. Farnesoid $X$ receptor (FXR) is known to activate miR-29a, reducing DPP-4 and the associated renal fibrosis. Statins also elevate SIRT1 by inhibiting miR-34a. SIRT1 inhibits claudin-1 and associated renal fibrosis.

endothelial dysfunction. miR-34a is an endogenous inhibitor of SIRT1, which promotes endothelial senescence. Renal tubular SIRT-1 attenuates diabetic albuminuria by epigenetically suppressing Claudin-1 overexpression in podocytes [70]. Atorvastatin improves CVD function by ameliorating miR-let7i level. Our research group recently suggested that the miR-let7s-FGFR1 axis inhibits TGF $\beta$ signaling [71]. Similarly, lovastatin ameliorates miR-33 family members, which in turn inhibit SREBP-2 and cholesterol synthesis. Farnesoid X Receptor (FXR) deficiency was found to cause diabetes to accelerate in type $1 \mathrm{DN}$ mice [72]. FXR inhibits SREBP-2 and elevates miR-29a, thereby ameliorating renal fibrosis [73]. miR-29s have been shown to ameliorate renal fibrosis by downregulating the DPP-4 level [74]. The exact mechanisms by which FXR works to protect DN are not known, but elevating miR-29a could be one possibility [72].

\section{Perspective}

The connection between atherosclerosis and glomerulosclerosis was suggested approximately 20 years ago by Diamond, who envisaged the foam cell, that is, the lipid overloaded macrophage, as the pivotal factor in both atherosclerosis and glomerulosclerosis [75,76]. Clinical studies suggest that lipid lowering drugs improve the cardiovascular functions in the DN patients, but no remarkable improvement has been found in the kidney outcome $[4,5]$. At the same time, clinical data revealed a reduction in the proteinuria in the statin-treated $\mathrm{DN}$ patients. Large-scale clinical trials that are prospective, randomized, and controlled are still lacking. Lipid control appears to be important in the prevention and treatment of DN. Targeting DAG over-production mediated PKC activation would allow for the utilization of cellular signaling pathways, which would be helpful for further studies on the control of DN. We previously discussed the role of ceramide and its effect on causing kidney disease. Targeting ceramide metabolism would be a therapeutic challenge in DN. Considering the microRNAs that target ceramide biosynthesis, degradation, and signaling mechanism, we could explore new insights and understandings into their role in the therapeutics of $\mathrm{DN}$.

\section{Conclusion}

The present review describes various aspects and implications of lipid lowering drugs in the treatment of DN. Enhanced PKC activation, as a result of hyperglycemiamediated DAG production and an increased rate of ceramide synthesis, is associated with impairment in renal functions. Targeting PKC activation and ceramide 
metabolism would be a therapeutic challenge in DN. At the same time, treatment with lipid lowering drugs contributes to the upregulation of antifibrotic microRNAs and associated mechanisms, which would affect the therapeutic potential in $\mathrm{DN}$.

\section{Abbreviations}

ACR: Albumin to creatinine ratio; aPKC: atypical PKC; BP: Blood pressure; a-SMA: a-Smooth muscle actin; CARDS: Collaborative Atorvastatin Diabetes Study; CKD: Chronic kidney disease; CPKC: Conventional PKC; DN: Diabetic nephropathy; DAG: Diacyglycerol; EPA: Eicosapentaenoic acid; ECM: Extracellular matrix protein; eGFR: Estimated glomerular filtration rate; FIELD: Fenofibrate Intervention and Event Lowering in Diabetes; FXR: Farnesoid X Receptor; HDL-c: High density lipoprotein cholesterol; HMG CoA: 3-hydroxy-3-methylglutaryl-CoA; JAS: Japanese atherosclerosis society; KLF2: Kruppel-like family of transcription factor; LDL-c: Low-density lipoprotein cholesterol; MRTFs: Myocardin related transcription factors; MAPK: Mitogen activated protein kinase; MCP-1: Monocyte chemotactic protein-1; NO: Nitric oxide; nPKC: New PKC; PANDA: Protection Against Nephropathy in Diabetes with Atorvastatin; PKCs: Protein kinase C; PAl-1: Plasminogen activator inhibitor-1; PS: Phosphatidylserine; PE: Phorbolester; PPARa: Peroxisome proliferator-activated receptor; PRK: PKC related kinases; PHN: Passive Heymann nephritis; ROS: Reactive oxygen species; SIRT1: Sirtuin1; SHARP: Study of Heart and Renal Protection; SRF: Serum response factor; SERBP: Sterol-Regulator Element-Binding Proteins; TGF 1 1: Transforming growth factor $\beta 1$; TXA2: Thromboxane A2; VEGF: Vascular endothelial growth factor; VSMCs: Vascular smooth muscle cells.

\section{Competing interests}

The authors declare no competing interest in this work.

\section{Authors' contributions}

SPS designed the study, wrote the review manuscript, and was involved in the discussion. SS was mainly involved in the editing process. DK made intellectual contributions. KK conceived of the project, provided intellectual contribution, and guided the manuscript writing and editing. All authors read and approved of the final manuscript.

\section{Acknowledgments}

The authors' laboratory is supported by a Grant from the Japan Society for the Promotion of Science to Keizo Kanasaki (26460403), Daisuke Koya (25670414, 25282028), and research grants from the Japan Research Foundation for Clinical Pharmacology to Keizo Kanasaki. Additionally, this work was partially supported by Grants for Promoted Research to Keizo Kanasaki (S2012-5, S2013-13) from Kanazawa Medical University. Keizo Kanasaki was also supported by several foundation grants from the following groups: the Novartis Foundation (Japan) for the Promotion of Science, the Takeda Science Foundation, and the Banyu Foundation. The authors declare that they have no financial conflict of interest. Swayam Prakash Srivastava is supported by the Japanese Government MEXT (Ministry of Education, Culture, Sports, Science, and Technology) Fellowship Program.

Received: 30 June 2014 Accepted: 8 August 2014

Published: 3 September 2014

\section{References}

1. Hirano T: Abnormal lipoprotein metabolism in diabetic nephropathy. Clin Exp Nephrol 2014, 18:206-209.

2. Chen HC, Guh JY, Chang JM: Role of lipid control in diabetic nephropathy. Kidney Int 2005, 67:S60-S62.

3. Barylski M, Nikfar S, Mikhailidis DP, Toth PP, Salari P, Ray KK, Pencina MJ, Rizzo M, Rysz J, Abdollahi M, Nicholls SJ, Banach M: Statins decrease all-cause mortality only in CKD patients not requiring dialysis therapy - a meta-analysis of 11 randomized controlled trials involving 21,295 participants. Pharmacol Res 2013, 72:35-44.

4. Ting RD, Keech AC, Drury PL, Donoghoe MW, Hedley J, Jenkins AJ, Davis TM, Lehto S, Celermajer D, Simes RJ, Rajamani K, Stanton K: Benefits and safety of long- term fenofibrate therapy in people with type 2 diabetes and renal impairment: the FIELD study. Diabetes Care 2012, 35:218-225
5. Coonrod BA, Ellis D, Becker DJ, Bunker CH, Kelsey SF, Lloyd CE, Drash AL, Kuller LH, Orchard TJ: Predictors of microalbuminuria in individuals with IDDM. Pittsburgh epidemiology of diabetes complications study. Diabetes Care 1993, 16:1376-1383.

6. Watts GF, Powerie JK, O'Brien SF, Shaw KM: Apolipoprotein B independently predicts progression of very-low-level albuminuria in insulin-dependent diabetes. Metabolism 1996, 45:1101-1107.

7. Parving HH, Rossing P, Hommel E, Smidt UM: Angiotensin converting enzyme inhibition in diabetic nephropathy: Ten year's experience. Am J Kidney Dis 1995, 26:99-107.

8. Ravid M, Brosh D, Ravid-Safrand D, Levy Z, Rachmani R: Main risk factors for nephropathy in type 2 diabetes mellitus are plasma cholesterol levels, mean blood pressure, and hyperglycemia. Arch Intern Med 1998, 158:998-1004.

9. Samuelsson O, Mulec H, Knight-Gibson C, Attman PO, Kron B, Larsson R, Weiss $L$, Wedel H, Alaupovic P: Lipoprotein abnormalities are associated with increased rate of progression of human chronic renal insufficiency. Nephrol Dial Transplant 1997, 12:1908-1915.

10. Krolewski AS, Warram JH, Christlieb AR: Hypercholesterolemia-a determinant of renal function loss and deaths in IDDM patients with nephropathy. Kidney Int Supp/ 1994, 45:S125-S131.

11. Fried LF: Effects of HMG-CoA reductase inhibitors (statins) on progression of kidney disease. Kidney Int 2008, 74:571-576.

12. Appel GB, Radhakrishnan J, Avram MM, DeFronzo RA, Escobar-Jimenez F, Campos MM, Burgess E, Hille DA, Dickson TZ, Shahinfar S, Brenner BM: Analysis of metabolic parameters as predictors of risk in the RENAAL study. Diabetes Care 2003, 26:1402-1407.

13. Kaysen GA, Gambertoglio J, Felts J, Hutchison FN: Albumin synthesis, albuminuria and hyperlipemia in nephrotic patients. Kidney Int 1987 31:1368-1376.

14. Sasaki T, Kurata H, Noumura K, Utsunomiya K, Ikeda Y: Amelioration of proteinuria with pravastatin in hypercholesterolemic patients with diabetes mellitus. Jpn J Med 1990, 29:156-163.

15. Shoji T, Nishizawa Y, Toyokawa A, Kawagishi T, Okuno Y, Morii H: Decreased albuminuria by pravastatin in hyperlipidemic diabetics. Nephron 1991, 59:664-665.

16. Tonolo G, Ciccarese M, Brizzi P, Puddu L, Secchi G, Calvia P, Atzeni MM, Melis MG, Maioli M: Reduction of albumin excretion rate in normotensive microalbuminuric type 2 diabetic patients during long-term simvastatin treatment. Diabetes Care 1997, 20:1891-1895.

17. Fried LF, Forrest KY, Ellis D, Chang Y, Silvers N, Orchard TJ: Lipid modulation in insulindependent diabetes mellitus: Effect on microvascular outcomes. J Diabetes Complications 2001, 15:113-119.

18. Scharschmidt LA, Gibbons NB, McGarry L, Berger P, Axelrod M, Janis R, Young HK: Effects of dietary fish oil on renal insufficiency in rats with subtotal nephrectomy. Kidney Int 1987, 32:700-709.

19. Salvati P, Ferti C, Ferrario RG, Lamberti E, Duzzi L, Bianchi G, Remuzzi G, Perico N, Benigni A, Braidotti P, Coggi G, Pugliese F, Patrono C: Role of enhanced glomerular synthesis of thromboxane $\mathrm{A} 2$ in progressive kidney disease. Kidney Int 1990, 38:447-458.

20. Gonin-Jmaa D, Senior DF: The hyperfiltration theory: progression of chronic renal failure and the effects of diet in dogs. J Am Vet Med Assoc 1995, 11:1411-1415.

21. Kelley V, Ferretti A, Shozo I, Strom T: A fish oil diet rich in eicosapentaenoic acid reduces cyclooxygenase metabolites, and suppresses lupus in MRL-1 pr mice. J Immunol 1985, 134:1914-1919.

22. Heifets M, Morrisey JJ, Purkerson ML, Morrison AR, Klahr S: Effect of dietary lipids on renal function in rats with subtotal nephrectomy. Kid Int 1987, 32:335-341.

23. Ahmad FK, He Z, King GL: Molecular targets of diabetic cardiovascular complications. Curr Drug Targets 2005, 6:487-494.

24. Li J, Gobe G: Protein kinase $C$ activation and its role in kidney disease. Nephrology 2006, 11:428-434.

25. Koya D, King GL: Protein Kinase C Activation and the Development of Diabetic Complications. Diabetes 1998, 47:859-866.

26. Tuttle KR, Anderson PW: A novel potential therapy for diabetic nephropathy and vascular complications: Protein kinase $\mathrm{C}$ beta inhibition. Am J Kidney Dis 2003, 42:456-465.

27. Bohlen HG, Nase GP, Jin JS: Multiple mechanisms of early hyperglycaemic injury of the rat intestinal microcirculation. Clin Exp Pharmacol Physiol 2002, 29:138-142. 
28. Kunisaki M, Bursell SE, Umeda F, Nawata H, King GL: Normalization of diacylglycerol-protein kinase $\mathrm{C}$ activation by vitamin $\mathrm{E}$ in aorta of diabetic rats and cultured rat smooth muscle cells exposed to elevated glucose levels. Diabetes 1994, 43:1372-1377.

29. Raptis AE, Viberti G: Pathogenesis of diabetic nephropathy. Exp Clin Endocrinol Diabetes 2001, 109:S424-S437.

30. Hao CM, Breyer MD: Physiologic and pathophysiologic roles of lipid mediators in the kidney. Kid Int 2007, 71:1105-1115.

31. Hannun YA: Functions of ceramide in coordinating cellular responses to stress. Science 1996, 274:1855-1859.

32. Pena LA, Fuks Z, Kolesnick R: Stress-induced apoptosis and the sphingomyelin pathway. Biochem Pharmacol 1997, 53:615-621

33. Zager RA, Conrad S, Lochhead K, Sweeney EA, Igarashi Y, Burkhart KM: Altered sphingomyelinase and ceramide expression in the setting of ischemic and nephrotoxic acute renal failure. Kid Int 1998, 53:573-582.

34. Kalhorn T, Zager RA: Renal cortical ceramide patterns during ischemic and toxic injury: assessments by HPLC-mass spectrometry. Am J Physiol 1999, 277:F723-F733.

35. Itoh Y, Yano T, Sendo T, Sueyasu M, Hirano K, Kanaide H, Oishi R: Involvement of de novo ceramide synthesis in radiocontrast-induced renal tubular cell injury. Kidney Int 2006, 69:288-297.

36. Yi F, Zhang AY, Janscha JL, Li PL, Zou AP: Homocysteine activates NADH/ NADPH oxidase through ceramide-stimulated Rac GTPase activity in rat mesangial cells. Kidney Int 2004, 66:1977-1987.

37. Morrissey Jj: Pleiotropic effects of amitriptyline ameliorate renal fibrosis. Kid Int 2009, 75:583-584.

38. Achar E, Achar RA, Paiva TB, Campos AH, Schor N: Amitriptyline eliminates calculi through urinary tract smooth muscle relaxation. Kidney Int 2003, 64:1356-1364

39. Hurwitz R, Frlinz K, Sndhoff K: The tricyclic antidepressant desipramine causes proteolytic degradation of lysosomal sphingomyelinase in human fibroblasts. Biol Chem Hoppe Seyler 1994, 375:447-450.

40. Achar E, Maciel TT, Collares CF, Teixeira VP, Schor N: Amitriptyline attenuates interstitial inflammation and ameliorates the progression of renal fibrosis. Kidney Int 2009, 75:596-604

41. Koya D, Campese VM: Statin use in patients with diabetes and kidney disease: The Japanese Experience. J Atherosd Thromb 2013, 20:407-424.

42. Teramoto T: Interim analysis of the Atorvastatin Lipid Lowering Assesment Survey in Patients with hypercholesterolemia (ALWAYS study). Therap Res 2011, 32:1587-1603. In Japanese.

43. Oda H, Keane WF: Recent advances in statins and the kidney. Kidney Int Suppl 1999, 56:S2-S5

44. Kimura S, Inoguchi T, Yokomizo H, Maeda Y, Sonoda N, Takayanagi R: Randomized comparison of pitavastatin and pravastatin treatment on the reduction of urinary albumin in patients with type 2 diabetic nephropathy. Diabetes Obes Metab 2012, 14:666-669.

45. Abe M, Maruyama N, Okada K, Matsumoto S, Matsumoto K, Soma M: Effects of lipid-lowering therapy with rosuvastatin on kidney function and oxidative stress in patients with diabetic nephropathy. J Atheroscler Thromb 2011, 18:1018-1028.

46. Rutter MK, Prais HR, Charlton-Menys V, Gittins M, Roberts C, Davies RR, Moorhouse A, Jinadev P, France M, Wiles PG, Gibson JM, Dean J, Kalra PA, Cruickshank JK, Durrington PN: Protection Against Nephropathy in Diabetes with Atorvastatin (PANDA): a randomized double-blind placebo-controlled trial of high- vs. low-dose atorvastatin(1). Diabet Med 2011, 28:100-108.

47. Colhoun HM, Betteridge DJ, Durrington PN, Hitman GA, Neil HA, Livingstone SJ, Charlton-Menys V, DeMicco DA, Fuller JH: CARDS Investigators: Effects of atorvastatin on kidney outcomes and cardiovascular disease in patients with diabetes: an analysis from the Collaborative Atorvastatin Diabetes Study (CARDS). Am J Kidney Dis 2009, 54:810-819.

48. Zoja C, Corna D, Rottoli D, Cattaneo D, Zanchi C, Tomasoni S, Abbate M, Remuzzi G: Effect of combining ACE inhibitor and statin in severe experimental nephropathy. Kidney Int 2002, 61:1635-1645.

49. O'Donnell MP, Kasiske BL, Kim Y, Atluru D, Keane WF: Lovastatin inhibits proliferation of rat mesangial cells. J Clin Invest 1993, 91:83-87.

50. Gaede P, Vedel P, Larsen N, Jensen GVH, Parving HH, Pedersen O: Multifactorial intervention and cardiovascular disease in patients with type 2 diabetes. N Engl J Med 2003, 348:383-393.

51. Huang $Y$, Hu Y: Lipid lowering agents in chronic kidney disease: do fibrate have a role? Nat Rev Cardiol 2013, 10:547.
52. Upadhyay A, Earley A, Lamont JL, Haynes S, Wanner C, Balk EM: Lipid-lowering therapy in persons with chronic kidney disease: a systematic review and meta-analysis. Ann Intern Med 2012, 157:251-262.

53. Danesh FR, Kanwar YS: Modulatory effect of HMG-CoA reductase inhibitors in diabetic microangiopathy. FASEB 2004, 18:805-815.

54. McCullough PA, Di Loreto MJ: Fibrates and cardiorenal outcomes. J Am Coll Cardiol 2012, 60:2072-2073.

55. Keech A, Simes RJ, Barter P, Best J, Scott R, Taskinen MR, Forder P, Pillai A, Davis T, Glasziou P, Drury P, Kesäniemi YA, Sullivan D, Hunt D, Colman P, D'Emden M, Whiting M, Ehnholm C, Laakso M: Effects of long-term fenofibrate therapy on cardiovascular events in 9795 people with type 2 diabetes mellitus (the FIELD study): randomised controlled trial. Lancet 2005, 366:1849-1861.

56. Mychaleckyj JC, Craven T, Nayak U, Buse J, Crouse JR, Elam M, Kirchner K, Lorber D, Marcovina S, Sivitz W, Sperl-Hillen J, Bonds DE, Ginsberg HN: Reversibility of fenofibrate therapy-induced renal function impairment in ACCORD type 2 diabetic participants. Diabetes Care 2012, 35:1008-1014.

57. Jun M, Zhu B, Tonelli M, Jardine MJ, Patel A, Neal B, Liyanage T, Keech A, Cass A, Perkovic V: Effects of fibrates in kidney disease: a systematic review and meta- analysis. J Am Coll Cardiol 2012, 60:2061-2071.

58. Udani SM, Bakris GL: Do fibrates truly preserve kidney function? Nat Rev Endocrinol 2011, 7:130-131.

59. Baigent C, Landray M, Leaper C, Altmann P, Armitage J, Baxter A, Cairns HS, Collins R, Foley RN, Frighi V, Kourellias K, Ratcliffe PJ, Rogerson M, Scoble JE, Tomson CR, Warwick G, Wheeler DC: First United Kingdom Heart and Renal Protection (UK-HARP-I) study: biochemical efficacy and safety of simvastatin and safety of low-dose aspirin in chronic kidney disease. Am J Kidney Dis 2005, 45:473-484.

60. Sharp Collaborative Group: Study of Heart and Renal Protection (SHARP): randomized trial to assess the effects of lowering low-density lipoprotein cholesterol among 9,438 patients with chronic kidney disease. Am Heart J 2010, 160:785-794.

61. Sharp Collaborative Group: The eff ects of lowering LDL cholesterol with simvastatin plus ezetimibe in patients with chronic kidney disease (Study of Heart and Renal Protection): a randomized placebo-controlled trial. Lancet 2011, 377:2181-2192.

62. Kato M, Arce L, Natarajn R: MicroRNAs and their role in progressive kidney diseases. Clin J American Soc Nephrol 2009, 4:1255-1266.

63. Srivastava SP, Koya D, Kanasaki K: MicroRNAs in kidney fibrosis and diabetic nephropathy: roles on EMT and EndMT. BioMed Res Int 2013, 2013:125469.

64. Hergenreider E, Heydt S, Treguer K, Boettger T, Horrevoets AJ, Zeiher AM, Scheffer MP, Frangakis AS, Yin X, Mayr M, Braun T, Urbich C, Boon RA, Dimmeler S: Atheroprotective communication between endothelial cells and smooth muscle cells through miRNAs. Nat Cell Biol 2012, 14:249-256.

65. Esau C, Kang X, Peralta E, Hanson E, Marcusson EG, Ravichandran LV, Sun Y, Koo S, Perera RJ, Jain R, Dean NM, Freier SM, Bennett CF, Lollo B, Griffey R: MicroRNA-143 regulates adipocyte differentiation. J Biol Chem 2004, 279:52361-52365.

66. Quintavalle $\mathrm{M}$, Condorelli G, Elia L: Arterial remodeling and atherosclerosis: miRNAs involvement. Vasc Pharmacol 2011, 55:106-110.

67. Long X, Miano JM: Transforming Growth Factor-b1 (TGF-b1) Utilizes Distinct Pathways for the Transcriptional Activation of MicroRNA 143/ 145 in Human Coronary Artery Smooth Muscle Cells. J Biol Chem 2011, 286:30119-30129.

68. Davis-Dusenbery BN, Chan MC, Reno KE, Weisman AS, Layne MD, Lagna G, Hata A: Down-regulation of Kruppel-like factor-4 (KLF4) by microRNA-143/145 is critical for modulation of vascular smooth muscle cell phenotype by transforming growth factor-b and bone morphogenetic protein 4 . J Biol Chem 2011, 286:28097-28110.

69. Tabuchi T, Satoh M, Itoh T, Nakamura M: MicroRNA-34a regulates the longevity-associated protein SIRT1 in coronary artery disease: effect of statins on SIRT1 and microRNA-34a expression. Clin Sci 2012, 123:161-171.

70. Hasegawa K, Wakino S, Simic P, Sakamaki Y, Minakuchi H, Fujimura K, Hosoya K, Komatsu M, Kaneko Y, Kanda T, Kubota E, Tokuyama H, Hayashi K, Guarente L, Itoh H: Renal tubular Sirt1 attenuates diabetic albuminuria by epigenetically suppressing Claudin-1 overexpression in podocytes. Nat Med 2013, 19:1496-1504.

71. Nagai T, Kanasaki M, Srivastava SP, Nakamura Y, Ishigaki Y, Kitada M, Shi S, Kanasaki K, Koya D: N-acetyl-seryl-aspartyl-lysyl-proline inhibits diabetesassociated kidney fibrosis and endothelial-mesenchymal transition. BioMed Res Int 2014, 2014:696475. 
72. Wang $X X$, Jiang $T$, Shen $Y$ : Diabetic nephropathy is accelerated by Farnesoid $X$ receptor deficiency and inhibited by Farnesoid $X$ receptor activation in a type 1 diabetes model. Diabetes 2010, 59:2916-2927.

73. Jiang T, Wang XX, Scherzer P, Wilson P, Tallman J, Takahashi H, Li J, Iwahashi M, Sutherland E, Arend L, Levi M: Farnesoid X receptor modulates renal lipid metabolism, fibrosis, and diabetic nephropathy. Diabetes 2007, 56:2485-2493.

74. Kanasaki K, Shi S, Kanasaki M, He J, Nagai T, Nakamura Y, Ishigaki Y, Kitada M, Srivastava SP, Koya D: Linagliptin-mediated DPP-4 inhibition ameliorates kidney fibrosis in streptozotocin-induced diabetic mice by inhibiting endothelial-to-mesenchymal transition in a therapeutic regimen. Diabetes 2014, 63:2120-2131.

75. Kwan BCH, Kronenberg F, Beddhu S, Cheung AK: Lipoprotein metabolism and lipid management in chronic didney disease. J Am Soc Nephrol 2007, 18:1246-1261.

76. Diamond JR: Analogous pathobiologic mechanisms in glomerulosclerosis and atherosclerosis. Kidney Int Supp/ 1991, 31:S29-S34.

doi:10.1186/1755-1536-7-12

Cite this article as: Srivastava et al:: Lipid mediators in diabetic nephropathy. Fibrogenesis \& Tissue Repair 2014 7:12.

\section{Submit your next manuscript to BioMed Central and take full advantage of:}

- Convenient online submission

- Thorough peer review

- No space constraints or color figure charges

- Immediate publication on acceptance

- Inclusion in PubMed, CAS, Scopus and Google Scholar

- Research which is freely available for redistribution 